\title{
Population Pharmacokinetics of Meropenem in Critically Ill Patients Undergoing Continuous Renal Replacement Therapy
}

\author{
Arantxazu Isla, ${ }^{1}$ Alicia Rodríguez-Gascón, ${ }^{1}$ Iñaki F. Trocóniz, ${ }^{2}$ Lorea Bueno, ${ }^{2}$ María Ángeles Solinís, ${ }^{1}$ \\ Javier Maynar, ${ }^{3}$ José Ángel Sánchez-Izquierdo ${ }^{4}$ and José Luis Pedraz ${ }^{1}$ \\ 1 Laboratory of Pharmacy and Pharmaceutical Technology, Faculty of Pharmacy, University of the Basque Country, \\ Vitoria-Gasteiz, Spain \\ 2 Department of Pharmacy and Pharmaceutical Technology, Faculty of Pharmacy, University of Navarra, Pamplona, Spain \\ 3 Intensive Care Unit, Santiago Apóstol Hospital, Vitoria-Gasteiz, Spain \\ 4 Intensive Care Unit, Doce de Octubre Hospital, Madrid, Spain
}

\section{Abstract}




\section{Background}

Meropenem is a carbapenem antibacterial with a wide spectrum of activity, including Gram-positive, Gram-negative and anaerobic microorganisms. It has shown clinical and bacteriological efficacy in the treatment of a wide range of serious infections in adults and children, and is prescribed for the treatment of infections in critically ill patients in intensive care due to its high degree of activity, its tolerability and its low incidence of toxicity. ${ }^{[1]}$

Meropenem has linear pharmacokinetic properties over the dose range of $0.25-2 \mathrm{~g}$, with an elimination half-life of approximately 1 hour in healthy volunteers..$^{[1,2]}$ Meropenem is eliminated by both metabolism and excretion. In healthy volunteers, 19-27\% of a $1 \mathrm{~g}$ dose is excreted as a microbiologically inactive open $\beta$ lactam metabolite, ${ }^{[3]}$ and up to $83 \%$ of the dose has been recovered unaltered in the urine. ${ }^{[4]}$

Meropenem is commonly administered to critically ill patients. The structural and pharmacokinetic characteristics of meropenem (i.e. water solubility, relatively small molecular weight [383.5 D] and low protein binding) allow for efficient removal of this drug by continuous renal replacement therapy (CRRT). Hydrophilic antimicrobials such as carbapenems are at higher risk of daily pharmacokinetic variations in critically ill patients ${ }^{[5]}$ Consequently, they should be more closely monitored, and their dosages should be streamlined according to the underlying diseases in order to prevent under- or overexposure,$^{[5]}$ to avoid treatment failure and to improve survival. The pharmacokinetics of meropenem in critically ill patients undergoing CRRT have been published previously, ${ }^{[6-16]}$ but a population pharmacokinetic analysis has never been performed. Population pharmacokinetics seek to (i) identify the measurable pathophysiological factors that cause changes in the dose-concentration relationship; (ii) quantify the extent of those changes; and (iii) estimate the magnitude of the unexplained variability in the patient population. ${ }^{[17]}$

Considering the high pharmacokinetic variability in critically ill patients and the lack of population pharmacokinetic information on meropenem in such patients, the purpose of this study was to develop a population pharmacokinetic model of meropenem in critically ill patients undergoing CRRT with the objectives of quantifying the degree of interindividual variability (IIV) in the model parameters and identifying the patient characteristics responsible for IIV.

\section{Methods}

\section{Study Design and Setting}

A prospective, open-label study was conducted in intensive care unit patients undergoing CRRT. Twenty patients ( 15 males and five females) meeting the following criteria were eligible for inclusion in the study: (i) age $>18$ years; (ii) treatment with CRRT for $>1$ day for $\geq 20 \mathrm{~h} / \mathrm{day}$; and (iii) isolated or expected causative pathogen susceptible to meropenem. The guardians of all patients provided written informed consent. Complete medical histories were obtained for all patients, and complete physical examinations and laboratory reviews of serum chemistry and haematology profiles were performed and reviewed before collection of samples for pharmacokinetic analysis. The study was conducted in accordance with good clinical practice and was approved by the medical ethical committees of the Santiago Apóstol Hospital (Vitoria-Gasteiz, Spain) and Doce de Octubre Hospital (Madrid, Spain).

\section{Renal Replacement Therapy}

All patients were undergoing CRRT, which has been defined as any extracorporeal blood purification therapy intended to substitute for impaired renal function over an extended period of time and applied for, or aimed at being applied for, 24 hours/day. ${ }^{[18]} \mathrm{In}$ our study, patients were specifically treated with continuous venovenous haemofiltration $(\mathrm{CVVH}, \mathrm{n}=10)$ or continuous venovenous haemodiafiltration (CVVHDF, $\mathrm{n}=10$ ).

Vascular access was obtained with 13.5 FG dual lumen catheters (Niagara, Bard Canada, Inc., Mississauga, Ontario, Canada). Haemodiafiltration machines (PRISMA, Hospal, Lyon, France; or MULTIFILTRATE, Fresenius Medical Care, Bad Homburg, Germany) were used with polyacrylonitrile AN69 HF $0.9 \mathrm{~m}^{2}$ membranes (PRISMA M100, Hospal) in 16 patients or polysulfone membranes (Ultraflux AV600S, $1.4 \mathrm{~m}^{2}$ Fresenius polysulfone ${ }^{\circledR}$, Fresenius Medical Care) in four patients. The blood flow was maintained between $100 \mathrm{~mL} / \mathrm{min}$ and $220 \mathrm{~mL} / \mathrm{min}$. In the CVVHDF procedures, the dialysate flow rate was $500 \mathrm{~mL} / \mathrm{h}$ or $1000 \mathrm{~mL} / \mathrm{h}$ into the dialysate compartment of the filter in a blood flow countercurrent direction. The ultrafiltrate obtained was replaced as clinically indicated at rates ranging from $800 \mathrm{~mL} / \mathrm{h}$ to $2500 \mathrm{~mL} / \mathrm{h}$. Replacement fluids were delivered prefilter.

\section{Drug Administration, Sampling Procedure and Analytical Methods}

Blood and dialysate-ultrafiltrate samples were obtained over one or more dosing intervals at steady state after administration of $500 \mathrm{mg}, 1000 \mathrm{mg}$ or $2000 \mathrm{mg}$ of meropenem every 6 or 8 hours by intravenous infusion. Blood samples $(4 \mathrm{~mL}$, using lithium heparin as an anticoagulant) were obtained from a prefilter device immediately before dosing, at the end of the infusion, at 20,30 and 45 minutes, and at 1,3 and 6 hours after the beginning of the infusion. Another sample was collected 8 hours after the beginning of the infusion in patients to whom meropenem was administered every 8 hours. Trough and peak samples were obtained on the following day or days in some patients. Simultaneously, dialysateultrafiltrate samples $(3 \mathrm{~mL})$ were taken directly from the dialysate- 
ultrafiltrate device. Blood specimens were centrifuged within 1 hour for 10 minutes at $1500 \times g$ at $4^{\circ} \mathrm{C}$. Plasma and dialysateultrafiltrate samples were immediately frozen at $-20^{\circ} \mathrm{C}$. The samples were then stored at $-80^{\circ} \mathrm{C}$ within 1 week and analysed within 1 month.

Determination of meropenem concentrations in plasma and dialysate-ultrafiltrate fluid was performed by validated ${ }^{[19,20]}$ highperformance liquid chromatography with a Waters apparatus (Waters Corp., Milford, MA, USA) coupled to a spectophotometric detector. ${ }^{[16]}$ The method used for plasma samples consisted of protein precipitation with acetonitrile, followed by washing with dichloromethane. The dialysate-ultrafiltrate samples did not require any preparation. Separation was performed on a $\mu$ Bondapak C18 (30 $\mathrm{cm} \times 3.9 \mathrm{~mm} \times 10 \mu \mathrm{m}$; Waters Corp.) with ultraviolet detection (296 nm). The mobile phase contained acetate buffer/ acetonitrile $(95: 5, \mathrm{v} / \mathrm{v})$ and was delivered at $2 \mathrm{~mL} / \mathrm{min}$. The assay was linear over the concentration ranges of $0.25-100 \mu \mathrm{g} / \mathrm{mL}$ for the plasma samples and $0.1-100 \mu \mathrm{g} / \mathrm{mL}$ for the dialysate-ultrafiltrate samples. The intra- and inter-day coefficients of variation (CV) ranged from $0.67 \%$ to $9.64 \%$ for the plasma samples and from $0.31 \%$ to $10.64 \%$ for the dialysate-ultrafiltrate samples at the three concentrations tested $(0.75 \mu \mathrm{g} / \mathrm{mL}, 10 \mu \mathrm{g} / \mathrm{mL}$ and $75 \mu \mathrm{g} / \mathrm{mL}$ for the plasma and $0.3 \mu \mathrm{g} / \mathrm{mL}, 5 \mu \mathrm{g} / \mathrm{mL}$ and $75 \mu \mathrm{g} / \mathrm{mL}$ for the dialysate-ultrafiltrate). The bias at these concentrations ranged from $2.02 \%$ to $14.44 \%$ for the plasma samples and from $0.11 \%$ to $9.85 \%$ for the dialysate-ultrafiltrate fluid. The lower limit of quantification was considered the lowest level included in the calibration curve $(0.25 \mu \mathrm{g} / \mathrm{mL}$ in plasma and $0.10 \mu \mathrm{g} / \mathrm{mL}$ in dialysate-ultrafiltrate), where the measures of the intra-day $\mathrm{CV}$ and bias were $11.69 \%$ and $10.10 \%$ for the plasma samples and $0.98 \%$ and $9.11 \%$ for the dialysate-ultrafiltrate samples. No interfering peaks were detected with the assay.

\section{Population Pharmacokinetic Data Analysis}

All data, including the concentrations of meropenem in plasma $\left(C_{p}\right)$ and in dialysate-ultrafiltrate $\left(C_{u}\right)$ from all of the patients participating in the study, were fitted simultaneously under the population approach using the first-order conditional estimation (FOCE) method with INTERACTION implemented in NONMEM version $\mathrm{V}$ software. ${ }^{[21]}$

IIV was modelled exponentially, and the residual variability for the two types of measurements (the plasma and dialysate-ultrafiltrate concentrations) was initially described with a combined error model; however, if during the model selection process one of the components (the additive or the proportional) of the residual error model was negligible, it was deleted from the model.

Selection between models was based on the precision of parameter estimates, goodness-of-fit plots, and the minimum value of the objective function $[-2 \times \log$ (likelihood); $-2 \mathrm{LL}]$ provided by NONMEM. A difference of 3.84 and 6.63 points in -2 LL between two nested models differing in one parameter is significant at the $5 \%$ and $1 \%$ levels, respectively. Since some of the models that were compared were not nested, -2LL was not used directly for comparative purposes, and the value of the Akaike Information Criteria (AIC), ${ }^{[22]}$ computed as equation 1 :

$$
\mathrm{AIC}=-2 \mathrm{LL}+2 \times \mathrm{Np}
$$

where $\mathrm{Np}$ is the number of the parameters in the model, was used instead. The model with the lowest value of the AIC, given that the precision of the model parameters and the data description were adequate, was selected.

Population model parameters were expressed as the corresponding estimate together with the \% CV computed as the ratio between the standard error provided by NONMEM and the estimate of the parameter multiplied by 100 . The magnitude of IIV was also expressed as the \% CV.

The model development process was performed in three steps. First, a base population model without incorporating covariates and capable of describing the data appropriately was selected. Disposition of the total drug in plasma was modelled using compartmental models parameterized in terms of the apparent volumes of distribution and total plasma and distribution clearances. The concentrations of meropenem in dialysate-ultrafiltrate were modelled as the product between the $\mathrm{C}_{\mathrm{p}}$ and the sieving coefficient $\left(\mathrm{S}_{\mathrm{c}}\right)$, a parameter to also be estimated and defined as the fraction of the drug eliminated across the membrane during CRRT. The significance of the off-diagonal elements of the $\Omega$ variance-covariance matrix was also evaluated at this stage.

The covariate model was built in the second step. Age, bodyweight (BW), dialysate plus ultrafiltrate flow (FLOW), creatinine clearance (CLCR) and the unbound drug fraction in plasma $\left(f_{u}\right)$ were the continuous covariates evaluated for significance. The type of membrane (MEMB; = 1 for AN69 or = 2 for polysulfone), CRRT (= 1 for CVVHDF or $=2$ for CVVH) and patient type ( 1 for septic or 2 for polytraumatized) were the categorical covariates studied. Table I lists the covariate information of the patients included in the current study. The relationships between covariates and individual pharmacokinetic parameter estimates were first explored graphically. Each covariate was added individually to the base model, and those covariates that showed a significant impact were then incorporated (starting with the covariate that led to the largest drop in -2LL) one at a time until the full covariate model was obtained. If an added covariate did not cause a significant decrease in $-2 \mathrm{LL}$, it was removed. This forward inclusion approach was followed by its reverse (backward elimination), whereby a covariate found not to be significant was dropped in favour of the simpler model. This procedure continued until no more covariates could be eliminated. During the forward inclusion and 
Table I. Summary of patient characteristics ${ }^{a}$

\begin{tabular}{|c|c|c|c|}
\hline Covariate & $\begin{array}{l}\text { All patients } \\
(n=20)\end{array}$ & $\begin{array}{l}\text { Septic patients } \\
(n=13)\end{array}$ & Polytraumatized patients $(n=7)$ \\
\hline Age $(y)$ & $56.2(20.5)[21-83]$ & $68.5(12.3)$ & $33.4(9.8)$ \\
\hline Bodyweight (kg) & 73.1 (6.9) [59-85] & $71.6(7.2)$ & $75.7(6.1)$ \\
\hline \multicolumn{4}{|l|}{ Gender (\%) } \\
\hline female & 25.0 & 30.8 & 14.3 \\
\hline male & 75.0 & 69.2 & 85.7 \\
\hline $\operatorname{CLCR}(\mathrm{mL} / \mathrm{min})^{\mathrm{b}}$ & $37.4(42.3)[0-118]$ & $22.0(32.4)$ & $66.1(45.8)$ \\
\hline Total protein concentration in plasma (g/dL) & $4.7(0.9)[3.1-6.0]$ & $4.6(0.9)$ & $5.0(0.7)$ \\
\hline Albumin concentration in plasma (g/dL) & $2.0(0.5)[0.9-2.9]$ & $2.0(0.7)$ & $1.9(0.1)$ \\
\hline Total bilirubin concentration in plasma (g/dL) & $0.9(0.4)[0.3-1.7]$ & $0.9(0.4)$ & $0.7(0.3)$ \\
\hline FLOW (mL/h) & $1910.0(616.4)[1000-2800]$ & $2284.6(299.6)$ & $1214.3(393.4)$ \\
\hline$f_{u}$ & $0.79(0.08)[0.63-0.98]$ & $0.79(0.09)$ & $0.79(0.07)$ \\
\hline SOFA score & $13.1(4.0)$ [8-21] & $11.9(2.8)$ & $15.1(5.2)$ \\
\hline APACHE II score & $19.4(6.8)[7-31]$ & $17.5(6.2)$ & $22.9(6.9)$ \\
\hline \multicolumn{4}{|l|}{ CRRT (\%) } \\
\hline CVVH & 50.0 & 38.5 & 71.4 \\
\hline CVVHDF & 50.0 & 61.5 & 28.6 \\
\hline
\end{tabular}

a Values are expressed as mean (SD) [range] unless specified otherwise.

b Determined as $\mathrm{CLCR}_{\mathrm{C}}=(\mathrm{Ucr} \bullet \mathrm{Vu}) /(\mathrm{Pcr} \bullet \mathrm{t})$, where $\mathrm{Ucr}$ and $\mathrm{Pcr}$ are the creatinine concentrations in urine and plasma, respectively, $\mathrm{Vu}$ is the urine volume collected in 24 hours and $t$ is the urinary collection time (1440 $\mathrm{min})$. $^{\text {[2] }}$

APACHE II = Acute Physiology and Chronic Health Evaluation II; CLCR = creatinine clearance; CRRT = continuous renal replacement therapy; CVVH = continuous venovenous haemofiltration; CVVHDF = continuous venovenous haemodiafiltration; FLOW = dialysate plus ultrafiltrate flow; $\mathbf{f}_{\mathbf{u}}=\mathbf{u n b o u n d}$ fraction of the drug in plasma; SOFA = sequential organ failure assessment.

backward exclusion approaches, the levels of significance used were $5 \%$ and $1 \%$, respectively.

The selected population model was evaluated in the third step using the visual predictive check $^{[24]}$ and parametric bootstrap.

\section{Visual Predictive Check}

Simulations of the meropenem plasma concentration-time profiles were performed from 1000 simulated individuals receiving a 500-mg or 2000-mg intravenous infusion for 20 minutes every 6 hours using the final model and its model parameter estimates, including IIV. For each dose group, the concentrationtime profiles corresponding to the 5th, 50th and 95th quantiles were represented together with the corresponding observations.

\section{Parametric Bootstrap}

One thousand datasets with the same characteristics as the original dataset were simulated on the basis of the selected model, and the model parameters were then re-estimated. Bias and precision were calculated by computing the median performance error (MPE) and the median of the absolute performance error (MAPE), respectively. For each simulation providing a successful minimization run, the performance error (PE) was calculated as equation 2:

$$
\mathrm{PE}=\frac{\mathrm{P}_{\text {sim }}-\mathrm{P}}{\mathrm{P}} \times 100
$$

where $\mathrm{P}_{\text {sim }}$ and $\mathrm{P}$ represent the parameter model estimate from a simulated dataset and the original dataset, respectively. The absolute performance error (APE) was defined as the absolute value of the PE.

\section{Results}

Meropenem was well tolerated in all patients; no adverse reactions attributable to meropenem treatment were reported, including tubulointerstitial nephritis.

The pharmacokinetic profiles were best described with a twocompartment model. The data supported the inclusion of IIV in total plasma clearance (CL), the apparent volume of distribution of the central compartment $\left(\mathrm{V}_{1}\right)$ and the $\mathrm{S}_{\mathrm{c}}$. The off-diagonal elements of the $\Omega$ variance-covariance matrix resulted in a nonsignificant effect $(\mathrm{p}>0.05)$. The additive and proportional elements of the combined error models were needed for both the $C_{p}$ and the $\mathrm{C}_{\mathrm{u}}$; however, the estimates of the residual variance differed between the two types of observations.

Among the examined covariates, age, BW, MEMB and CRRT did not show significant covariate effects $(p>0.05)$ on any of the 
pharmacokinetic parameters. During the forward covariate inclusion approach, $\mathrm{CL}_{\mathrm{CR}}$, FLOW, and the patient type were found to be significant for CL $(p<0.05)$. CL was described as the sum of the renal clearance (affected by CLCR and the patient type), nonrenal clearance (not affected by any of the explored covariates) and extracorporeal clearance (calculated as the product between FLOW and the $S_{c}$ ). In the case of the $V_{1}$, the $f_{u}$ and the patient type were the covariates exerting a significant effect $(p<0.05)$. The following equations describe $\mathrm{CL}$ and the $\mathrm{V}_{1}$ in the full model, incorporating all of the covariates selected during the forward inclusion approach (equation 3):

$$
\begin{aligned}
& \mathrm{CL}=\theta_{\mathrm{CL}}+\theta_{\mathrm{CL}} \mathrm{CR}_{\text {(septic })} \times \mathrm{CL}_{\mathrm{CR}}+\mathrm{S}_{\mathrm{c}} \times \text { FLOW } \\
& \mathrm{CL}=\theta_{\mathrm{CL}}+\theta_{\mathrm{CL}} \mathrm{CR \text {(polytraumatized } )} \times \mathrm{CL}_{\mathrm{CR}}+\mathrm{S}_{\mathrm{c}} \times \text { FLOW } \\
& \mathrm{V}_{1}=\theta_{\mathrm{V} \text { (septic) }} \times \mathrm{f}_{\mathrm{u}} \\
& \mathrm{V}_{1}=\theta_{\mathrm{V} \text { (polytraumatized) }} \times \mathrm{f}_{\mathrm{u}}
\end{aligned}
$$

Deletion from the full model of the $\mathrm{f}_{\mathrm{u}}$ and FLOW covariates did not elicit a significant increase in $-2 L L(p>0.01)$. The parameter estimates of the final selected model, which incorporates the significant covariates $\mathrm{CL}_{\mathrm{CR}}$ and the patient type, are presented in table II, where it can be observed that all parameters were estimated with adequate precision.

Inclusion of the selected covariates in the model decreased the degree of IIV, with respect to the basic model, from $150 \%$ to $38 \%$ in CL and from $85 \%$ to $45 \%$ in the $\mathrm{V}_{1}$. The IIV associated with the $\mathrm{S}_{\mathrm{c}}$ was $18 \%$. The additive and proportional residual errors corresponding to the $\mathrm{C}_{\mathrm{p}}$ were $0.22 \mathrm{mg} / \mathrm{L}$ and $21 \%$, respectively, and those corresponding to the $\mathrm{C}_{\mathrm{u}}$ were $0.15 \mathrm{mg} / \mathrm{L}$ and $25 \%$, respectively.

The mean population estimate of CL was a linear function of $\mathrm{CL}_{\mathrm{CR}}$ in both groups of patients, with an intercept of $6.63 \mathrm{~L} / \mathrm{h}$ and slopes of 0.063 and 0.72 for septic and polytraumatized patients, respectively. The $\mathrm{V}_{1}$ was also dependent on the patient type, with values of $15.7 \mathrm{~L}$ for septic patients and $69.5 \mathrm{~L}$ for polytraumatized patients. The population CL was $15 \mathrm{~L} / \mathrm{h}$, and the population apparent volume of distribution of the peripheral compartment was $19.8 \mathrm{~L}$.

The goodness-of-fit plots presented in figure 1, together with the results of the visual predictive check shown in figure 2, confirmed graphically that the selected model was supported by data. The MPE and MAPE values obtained from 966 successful minimization runs were below $10 \%$ and $30 \%$ for most of the model parameters, with the exception of the IIV of CL $(\mathrm{MPE}=-17 \%)$ and $\theta_{\mathrm{CLCR}(\text { septic) }}$ and the IIV of the $\mathrm{S}_{\mathrm{c}}$ (MAPE $=46 \%$ and $41 \%$, respectively).

Figure 3 explores the impact of the two selected covariates, $\mathrm{CL}_{\mathrm{CR}}$ and the patient type, on the plasma concentration-time profiles of meropenem administered as an intravenous infusion of $500 \mathrm{mg}$ or $2000 \mathrm{mg}$. It is clear that both covariates are likely to have a clinical impact.

\section{Discussion}

The objective of this analysis was to develop a population pharmacokinetic model of meropenem in critically ill patients undergoing CRRT by using plasma and dialysate-ultrafiltrate concentration data from 20 patients. Several previous studies have reported on the pharmacokinetics of meropenem in critically ill patients undergoing CRRT by using traditional pharmacokinetic analysis. ${ }^{[6-16]}$ In contrast, by using population pharmacokinetic methods, this study extends the analysis to address potentially important covariates in order to estimate their influence on pharmacokinetic parameters and the magnitude of the variability that could not be assessed in the other studies. A bibliographical search in MEDLINE and using the WINSPIRS computer system failed to identify other studies of population pharmacokinetics of meropenem in patients undergoing CRRT.

A two-compartment model was preferred to a one-compartment model, as it provided a much better fit when base models without incorporation of covariates were evaluated in the first step

\begin{tabular}{|c|c|c|}
\hline Parameter or covariate model & Estimate $(\% \mathrm{CV})$ & IIV (\%CV) \\
\hline \multicolumn{2}{|l|}{$\mathrm{CL}=\theta \mathrm{CL}+\theta \mathrm{CLCR} \times \mathrm{CLCR}$} & \multirow[t]{4}{*}{$38(2)$} \\
\hline$\theta \mathrm{CL}$ & $6.63(13)$ & \\
\hline$\theta$ CLCR(septic) & $0.064(41)$ & \\
\hline$\theta$ CLCR(polytraumatized) & $0.72(21)$ & \\
\hline \multicolumn{3}{|l|}{$\mathrm{V}_{1}(\mathrm{~L})$} \\
\hline $\mathrm{V}_{1 \text { (septic) }}$ & $15.7(10)$ & \multirow[t]{2}{*}{$45(35)$} \\
\hline $\mathrm{V}_{1 \text { (polytraumatized) }}$ & $69.5(18)$ & \\
\hline CLD (L/h) & $15(14)$ & $\mathrm{NE}$ \\
\hline $\mathrm{V}_{2}(\mathrm{~L})$ & $19.8(11)$ & NE \\
\hline $\mathrm{S}_{\mathrm{c}}$ & $0.72(6.3)$ & $18(47)$ \\
\hline \multicolumn{2}{|l|}{ Additive error $(\mathrm{mg} / \mathrm{L})$} & \multirow[t]{3}{*}{ NA } \\
\hline$C_{p}$ & $0.22(20)$ & \\
\hline $\mathrm{C}_{\mathrm{u}}$ & $0.15(85)$ & \\
\hline \multicolumn{2}{|l|}{ Proportional error (\%) } & \multirow[t]{3}{*}{ NA } \\
\hline $\mathrm{C}_{\mathrm{p}}$ & \multirow{2}{*}{$\begin{array}{l}21(11) \\
25(22) \\
\end{array}$} & \\
\hline $\mathrm{C}_{\mathrm{u}}$ & & \\
\hline \multicolumn{3}{|c|}{$\begin{array}{l}\mathbf{C L}=\text { total plasma clearance; } \mathbf{C L} \mathbf{C R}=\text { creatinine clearance; } \mathbf{C L}_{\mathbf{D}}= \\
\text { distribution clearance; } \mathbf{C}_{\mathbf{p}}=\text { concentrations of meropenem in plasma; } \mathbf{C}_{\mathbf{u}}= \\
\text { concentrations of meropenem in dialysate-ultrafiltrate; IIV }=\text { interindividual } \\
\text { variability; NA } \mathbf{N A} \text { not applicable; } \mathbf{N E}=\text { not estimated; } \mathbf{S}_{\mathbf{c}}=\text { sieving } \\
\text { coefficient; } \mathbf{V}_{\mathbf{1}}=\text { apparent volume of distribution of the central } \\
\text { compartment; } \mathbf{V}_{\mathbf{2}}=\text { apparent volume of distribution of the peripheral } \\
\text { compartment. }\end{array}$} \\
\hline
\end{tabular}
of the model building. The precision of the parameter estimates in

Table II. Population pharmacokinetic model parameter estimates of meropenem after intravenous administration 

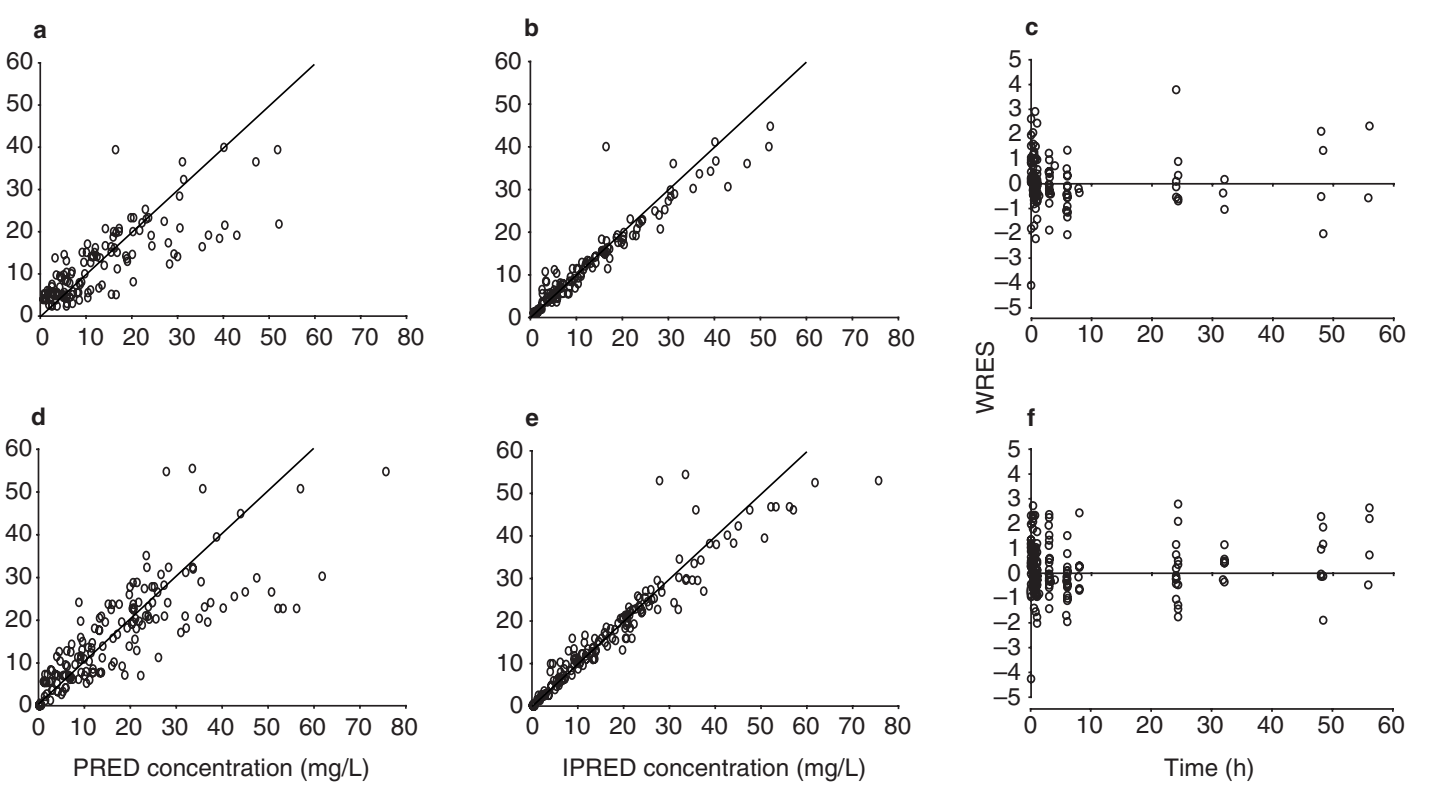

Fig. 1. Goodness-of-fit plots obtained from the final population pharmacokinetic model selected for meropenem. (a), (b) and (c) correspond to the total plasma concentrations; (d), (e) and (f) correspond to the dialysate-ultrafiltrate concentrations. DV = observed values; IPRED = individual model predictions; PRED = typical population predictions; WRES = weighted residuals provided by NONMEM.

the selected structural model suggested that the model parameters were estimated with reasonable precision. The goodness of fit was confirmed by the plots of population and individual model predictions versus observations and weighted residuals versus time for both the plasma data and the dialysate-ultrafiltrate data. When possible, the comparison between the pharmacokinetic parameters obtained by the population analysis method and the traditional approach can serve as an indicator of the accuracy of the population pharmacokinetic models. In this study, the pharmacokinetic parameters were consistent with the values calculated by the traditional approach previously published. ${ }^{[16]}$

Population pharmacokinetics are a very useful instrument to provide quantitative inspection of the influence of several pathophysiological and clinical covariates on the pharmacokinetic profile of drugs. In our study, CLCR was found to have a significant correlation with $\mathrm{CL}$ during the development of the covariate model, which is in accordance with the established finding that up to $83 \%$ of the administered dose of meropenem is recovered in the urine ${ }^{[4]}$ However, the influence of $\mathrm{CL}_{\mathrm{CR}}$ differed between septic and polytraumatized patients. In this way, renal clearance of meropenem varied extensively from septic patients to severely polytraumatized patients. The $\mathrm{V}_{1}$ also differed between these two types of patients.

Other studied covariates such as age, BW, FLOW, $\mathrm{f}_{\mathrm{u}}$, MEMB and CRRT were not included in the final model. However, there should probably be another covariate, not included in the protocol, that would have allowed us to specify and determine why meropenem showed different pharmacokinetics in septic and polytraumatized patients. In fact, polytraumatized patients received large quantities of intravenous fluid during an extended treatment period, which could have resulted in an expanded extracellular compartment, as occurs with other drugs. ${ }^{[25-30]}$ However, the volumes of fluid administered in both groups of patients, among other possible parameters, were not included in the data collection sheet when the study was designed. According to all of this, we must emphasize the importance of the patient's clinical status in
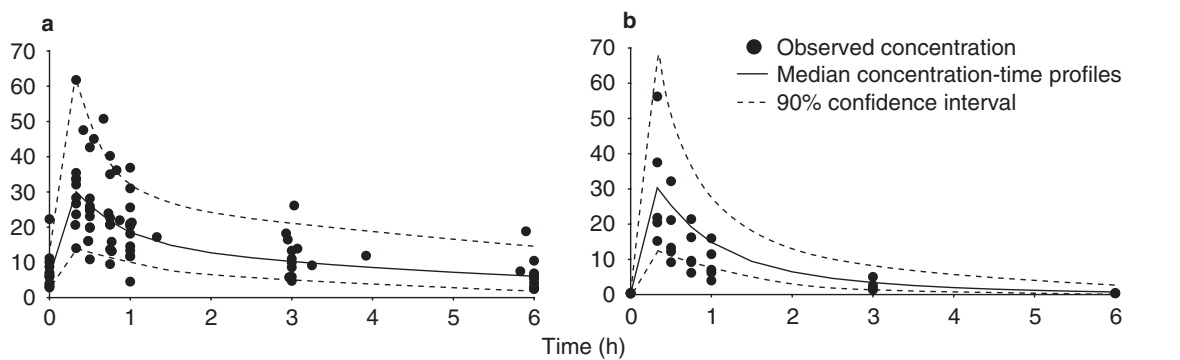

Fig. 2. Results of the model exploration exercise where total plasma concentration-time profiles of meropenen were obtained from 1000 simulated individuals receiving a 20-min infusion of (a) $500 \mathrm{mg}$ or (b) $2000 \mathrm{mg}$. 

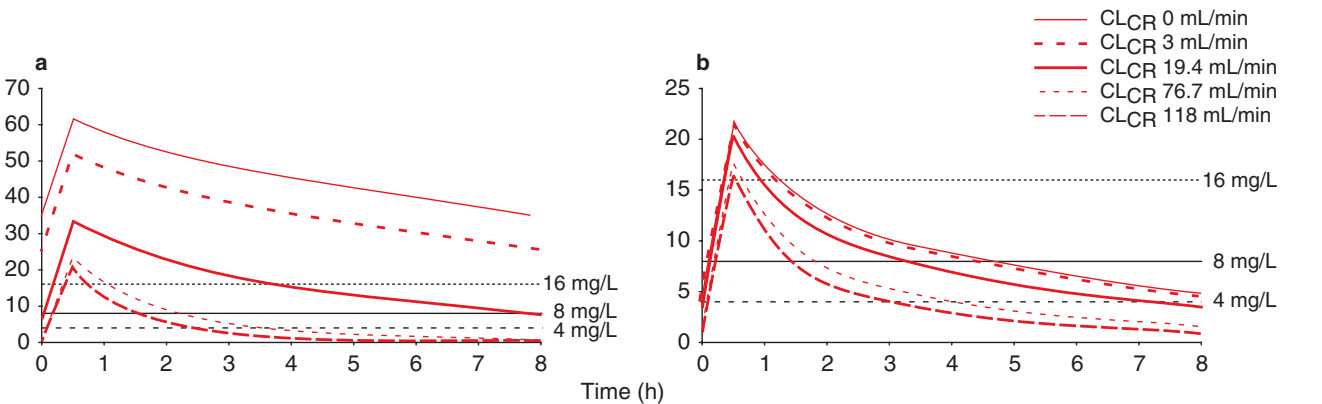

Fig. 3. Typical population simulated plasma concentration-time profiles of meropenem administered as an intravenous 20-min infusion of (a) 500 mg or (b) $2000 \mathrm{mg}$ to patients as a function of creatinine clearance (CLCR). The values of $\mathrm{CL}_{\mathrm{CR}}$ chosen for the simulation exercise correspond to the minimum, first, second and third percentiles and the maximum values seen in the studied populations.

characterizing the pharmacokinetic profile of the drug in critically ill patients.

The potential clinical significance of the statistically-based selected covariates was studied by computer simulations. Figure 3 shows the effects of $\mathrm{CL}_{\mathrm{CR}}$ on the typical population pharmacokinetic profiles of meropenem for each type of patient and under the same dosing schedule used in the current study. First, it appears clear that sepsis and polytrauma have an important effect on the pharmacokinetic characteristics of meropenem. Then, $\mathrm{CL}_{\mathrm{CR}}$ has a much greater impact on plasma disposition of meropenem in septic patients than in polytraumatized patients.

These pharmacokinetic results emphasize that meropenem CL is higher in polytraumatized patients and in those with better renal function. However, pharmacodynamic considerations should also be taken into account. For $\beta$-lactam antibacterial agents, the pharmacokinetic/pharmacodynamic predictor of clinical efficacy is the time during which the serum drug concentration is above the minimum inhibitory concentration ( $\mathrm{T}>\mathrm{MIC}$ ) of the infecting pathogen. In critically ill patients, a T>MIC of $100 \%$ should be obtained. The US National Committee for Clinical Laboratory Standards ${ }^{[31]}$ has established breakpoints for susceptible, intermediate susceptible and resistant strains of Enterobacteriaceae, Pseudomonas and Staphylococcus of $\leq 4 \mathrm{mg} / \mathrm{L}, 8 \mathrm{mg} / \mathrm{L}$ and $\geq 16 \mathrm{mg} / \mathrm{L}$, respectively. The breakpoint for susceptible Haemophi- lus and viridans group streptococci is $\leq 0.5 \mathrm{mg} / \mathrm{L}$, and the value for susceptible Streptococcus pneumoniae and Neisseria meningitidis is $\leq 0.25 \mathrm{mg} / \mathrm{L}$. Our results (figure 3) show that polytraumatized patients may not achieve adequate efficacy indexes to deal with specific infections, especially Enterobacteriaceae, Pseudomonas and Staphylococcus, even after receiving high doses of meropenem. Septic patients with conserved renal function will probably not achieve plasma drug concentrations above the MIC of some pathogens during the entire dosing interval. In these cases, administration of meropenem as a continuous infusion would be recommendable for optimization of antimicrobial therapy when an isolated or expected causative pathogen has an MIC of $\geq 4 \mathrm{mg} / \mathrm{L}$. Continuous infusion of other $\beta$-lactams, such as ceftazidime, ${ }^{[32]}$ has also been recommend in critically ill patients with severe acute renal failure undergoing CRRT. Table III summarizes the recommended continuous infusion protocol of meropenem for critically septic patients and polytraumatized patients when pathogens with MIC values of $4 \mathrm{mg} / \mathrm{L}, 8 \mathrm{mg} / \mathrm{L}$ and $16 \mathrm{mg} / \mathrm{L}$ are isolated. This protocol is based on the population pharmacokinetic model developed in the present study. Infections caused by pathogens with an MIC of $\geq 8 \mathrm{mg} / \mathrm{L}$ should not be treated with meropenem in polytraumatized patients without or with moderate renal failure because excessive doses of meropenem would be necessary.

Table III. Continuous intravenous infusion rates of meropenem in septic and polytraumatized patients with different degree of renal function that allow achievement of plasma drug concentrations above $4 \mathrm{mg} / \mathrm{L}, 8 \mathrm{mg} / \mathrm{L}$ and $16 \mathrm{mg} / \mathrm{L}$

\begin{tabular}{|c|c|c|c|c|c|c|c|}
\hline \multirow[t]{3}{*}{ Patient type } & \multirow{3}{*}{$\begin{array}{l}\text { MIC } \\
(\mathrm{mg} / \mathrm{L})\end{array}$} & \multicolumn{6}{|c|}{ Infusion rate $[\mathrm{mg} / \mathrm{h}$ (mg/day)] } \\
\hline & & \multicolumn{6}{|c|}{ CLCR (mL/min) } \\
\hline & & 0 & 10 & 25 & 50 & 75 & 100 \\
\hline \multirow[t]{3}{*}{ Septic } & 4 & $27(637)$ & $29(698)$ & $33(790)$ & $39(944)$ & $46(1097)$ & $52(1251)$ \\
\hline & 8 & $53(1273)$ & $58(1396)$ & $66(1580)$ & 79 (1887) & 91 (2195) & $104(2502)$ \\
\hline & 16 & $106(2546)$ & $116(2792)$ & $132(3160)$ & $157(3775)$ & $183(4389)$ & $209(5004)$ \\
\hline \multirow[t]{3}{*}{ Polytraumatized } & 4 & $27(637)$ & $55(1328)$ & $99(2365)$ & $171(4093)$ & $243(5821)$ & 315 (7549) \\
\hline & 8 & $53(1273)$ & $111(2655)$ & 197 (4729) & 341 (8185) & $485(11641)$ & $629(15097)$ \\
\hline & 16 & $106(2546)$ & $221(5311)$ & $394(9458)$ & $682(16370)$ & 970 (23 282) & 1258 (30 194) \\
\hline
\end{tabular}

CLCR = creatinine clearance; $\mathbf{M I C}=$ minimum inhibitory concentration . 


\section{Conclusion}

A population pharmacokinetic model of meropenem in intensive care patients on CRRT was developed and validated. The two-compartment model gave a better description of the data than the one-compartment model and was retained as the base model.

$\mathrm{CL}_{\mathrm{CR}}$ and the patient type (whether the patient was septic or polytraumatized) were identified as significant covariates that accounted for part of the variability in the pharmacokinetic behaviour of this drug in these patients. The population pharmacokinetic model developed in this study has been helpful for establishing dosage regimens of meropenem administered by continuous infusion to patients undergoing CRRT, taking into account that the objective will be to guarantee drug concentrations above the MIC of the causative pathogen because meropenem is a time-dependent activity agent.

\section{Acknowledgements}

The authors would like to thank the Basque Government for the predoctoral research grant to Arantxazu Isla. No sources of funding were used to assist in the preparation of this study. The authors have no conflicts of interest that are directly relevant to the content of this study.

\section{References}

1. Drusano GL, Hutchison M. The pharmacokinetics of meropenem. Scand J Infect Dis 1995; 96 Suppl.: 11-6

2. Dandekar PK, Maglio D, Sutherland CA, et al. Pharmacokinetics of meropenem 0.5 and $2 \mathrm{~g}$ every 8 hours as a 3-hour infusion. Pharmacotherapy 2003 Aug; 23 (8): $988-91$

3. Hurst M, Lamb HM. Meropenem: a review of its use in patients in intensive care. Drugs 2000 Mar; 59 (3): 653-80

4. Mouton JW, van den Anker JN. Meropenem clinical pharmacokinetics. Clin Pharmacokinet 1995 Apr; 28 (4): 275-86

5. Pea F, Viale P, Furlanut M. Antimicrobial therapy in critically ill patients: a review of pathophysiological conditions responsible for altered disposition and pharmacokinetic variability. Clin Pharmacokinet 2005; 44 (10): 1009-34

6. Thalhammer F, Hörl WH. Pharmacokinetics of meropenem in patients with renal failure and patients receiving renal replacement therapy. Clin Pharmacokinet 2000 Oct; 39 (4): 271-9

7. Thalhammer F, Schenk P, Burgmann H, et al. Single-dose pharmacokinetics of meropenem during continuous venovenous hemofiltration. Antimicrob Agents Chemother 1998 Sep; 42 (9): 2417-20

8. Krueger WA, Schroeder TH, Hutchison M, et al. Pharmacokinetics of meropenem in critically ill patients with acute renal failure treated by continuous hemodiafiltration. Antimicrob Agents Chemother 1998 Sep; 42 (9): 2421-4

9. Meyer MM, Munar MY, Kohlhepp SJ, et al. Meropenem pharmacokinetics in a patient with multiorgan failure from meningococcemia undergoing continuous venovenous hemodiafiltration. Am J Kidney Dis 1999 Apr; 33 (4): 790-5

10. Tegeder I, Neumann F, Bremer F, et al. Pharmacokinetics of meropenem in critically ill patients with acute renal failure undergoing continuous venovenous hemofiltration. Clin Pharmacol Ther 1999 Jan; 65 (1): 50-7

11. Giles LJ, Jennings AC, Thomson AH, et al. Pharmacokinetics of meropenem in intensive care unit patients receiving continuous veno-venous hemofiltration or hemodiafiltration. Crit Care Med 2000 Mar; 28 (3): 632-7

12. Ververs TF, van Dijk A, Vinks SA, et al. Pharmacokinetics and dosing regimen of meropenem in critically ill patients receiving continuous venovenous hemofiltration. Crit Care Med 2000 Oct; 28 (10): 3412-6
13. Valtonen M, Tiula E, Backman JT, et al. Elimination of meropenem during continuous veno-venous haemofiltration and haemodiafiltration in patients with acute renal failure. J Antimicrob Chemother 2000 May; 45 (5): 701-4

14. Krueger WA, Neeser G, Schuster H, et al. Correlation of meropenem plasma levels with pharmacodynamic requirements in critically ill patients receiving continuous veno-venous hemofiltration. Chemotherapy 2003 Dec; 49 (6): 280-6

15. Robatel C, Decosterd LA, Biollaz J, et al. Pharmacokinetics and dosage adaptation of meropenem during continuous venovenous hemodiafiltration in critically ill patients. J Clin Pharmacol 2003 Dec; 43 (12): 1329-40

16. Isla A, Maynar J, Sánchez-Izquierdo JA, et al. Meropenem and continuous renal replacement therapy: in vitro permeability of 2 continuous renal replacement therapy membranes and influence of patient renal function on the pharmacokinetics in critically ill patients. J Clin Pharmacol 2005 Nov; 45 (11): 1294-304

17. Sun H, Fadiran EO, Jones CD, et al. Population pharmacokinetics: a regulatory perspective. Clin Pharmacokinet 1999 Jul; 37 (1): 41-58

18. Bellomo R, Ronco C. Nomenclature for continuous renal replacement therapies. In: Ronco C, Bellomo R, editors. Critical care nephrology. Dordrecht: Kluwer Academic Publishers; 1998: 1169-76

19. Shah VP, Midha KK, Findlay JW, et al. Bioanalytical method validation: a revisit with a decade of progress. Pharm Res 2000 Dec; 17 (12): 1551-7

20. US FDA. Guidance for industry: bioanalytical methods validation for human studies. Rockville (MD): Center for Drug Evaluation and Research, 1998

21. Beal SL, Sheiner LB. NONMEM user's guide. San Francisco (CA): University of California NONMEM Project Group, 1992

22. Akaike H. A new look at the statistical model identification. IEEE Transactions on Automated Control 1974; 19: 716-23

23. Wuyts B, Bernard D, Van den Noortgate N, et al. Reevaluation of formulas for predicting creatinine clearance in adults and children, using compensated creatinine methods. Clin Chem 2003 Jun; 49 (6 Pt 1): 1011-4

24. Holford N. The visual predictive check: superiority to standard diagnostic (Rorschach) plots [abstract/poster no. 738; online]. Annual Meeting of the Population Approach Group in Europe, 2005 Jun 16-17; Pamplona. Available from URL: http://www.page-meeting.org/?abstract=738 [Accessed 2007 Dec 6]

25. Hanes SD, Wood GC, Herring V, et al. Intermittent and continuous ceftazidime infusion for critically ill trauma patients. Am J Surg 2000 Jun; 179 (6): 436-40

26. Reed RL, Ericsson CD, Wu A, et al. The pharmacokinetics of prophylactic antibiotics in trauma. J Trauma 1992 Jan; 32 (1): 21-7

27. Townsend PL, Fink MP, Stein KL, et al. Aminoglycoside pharmacokinetics: dosage requirements and nephrotoxicity in trauma patients. Crit Care Med 1989 Feb; 17 (2): 154-7

28. Botha FJ, van der Bijl P, Seifart HI, et al. Fluctuation of the volume of distribution of amikacin and its effect on once-daily dosage and clearance in a seriously ill patient. Intensive Care Med 1996 May; 22 (5): 443-6

29. Fernández de Gatta MM, Méndez ME, Romano $S$, et al. Pharmacokinetics of amikacin in intensive care unit patients. J Clin Pharm Ther 1996 Dec; 21 (6): $417-21$

30. Arzuaga A, Maynar J, Gascón AR, et al. Influence of renal function on the pharmacokinetics of piperacillin/tazobactam in intensive care unit patients during continuous venovenous hemofiltration. J Clin Pharmacol 2005 Feb; 45 (2): $168-76$

31. Performance standards for antimicrobial susceptibility testing: fourteenth informational supplement [NCCLS document no. M100-S14, 2004]. Wayne (PA): US National Committee for Clinical Laboratory Standards (NCCLS), 2007

32. Mariat C, Venet C, Jehl F, et al. Continuous infusion of ceftazidime in critically ill patients undergoing continuous venovenous haemodiafiltration: pharmacokinetic evaluation and dose recommendation. Crit Care 2006 Feb; 10 (1): R26

Correspondence: Dr José Luis Pedraz, Laboratorio de Farmacia y Tecnología Farmacéutica, Facultad de Farmacia, Paseo de la Universidad nº 7, 01006 Vitoria-Gasteiz, Spain.

E-mail: joseluis.pedraz@ehu.es 